\title{
Visual Perception of Egocentric Distance as Assessed by Triangulation
}

\author{
Sergio S. Fukusima \\ University of São Paulo
}

\author{
Jack M. Loomis \\ University of California, Santa Barbara
}

\author{
José A. Da Silva \\ University of São Paulo
}

\begin{abstract}
Two triangulation methods for measuring perceived egocentric distance were examined. In the triangulation-by-pointing procedure, the observer views a target at some distance and, with eyes closed, attempts to point continuously at the target while traversing a path that passes by it. In the triangulation-by-walking procedure, the observer views a target and, with eyes closed, traverses a path that is oblique to the target; on command from the experimenter, the observer turns and walks toward the target. Two experiments using pointing and 3 using walking showed that perceived distance, averaged over observers, was accurate out to $15 \mathrm{~m}$ under full-cue conditions. For target distances between 15 and $25 \mathrm{~m}$, the evidence indicates slight perceptual underestimation. Results also show that observers, on average, were accurate in imaginally updating the locations of previously viewed targets.
\end{abstract}

The term visual space (or visually perceived space) refers to a perceptual representation of the immediate physical environment that exists independently of any of the particular spatial behaviors it helps to control. Much vision research has been devoted to establishing the functional properties of visual space and the mechanisms that underlie it. A major goal of such research has been to characterize the mapping from physical to visual space under different conditions of information availability, but ultimately the goal must be to predict visual space solely in terms of its sensory inputs and internal determinants (e.g., intrinsic noise, observer assumptions, etc.).

Because visual direction is perceived accurately, most space perception research has examined the perception of egocentric distance (i.e., the distance from the object to the observer) and the perception of exocentric distance (i.e., the distance between two targets lying in the same visual direction or, more generally, the distance between any two locations). Because we believe that the perception of egocentric

Sergio S. Fukusima and José A. Da Silva, Department of Psychology, University of São Paulo, Ribeirão Preto, São Paulo, Brazil; Jack M. Loomis, Department of Psychology, University of California, Santa Barbara.

This research was supported by Conselho Nacional de Pesquisas fellowship 200104/89.6/PH awarded to Sergio S. Fukusima and National Science Foundation Grant DBS 8919383 awarded to Jack M. Loomis. A preliminary report of this research was presented at the November 1991 meeting of the Psychonomic Society held in San Francisco. We thank Gideon Bernstein, Michael Feakins, Mark Getzoff, Peter Hegarty, Omar Noorzad, and Danica Vanstekelenburg for their assistance with the experiments.

Correspondence concerning this article should be addressed to either Sergio S. Fukusima, Department of Psychology, FFCLRP, University of São Paulo, Ribeirão Preto, São Paulo, Brazil, CEP 14050-901, or Jack M. Loomis, Department of Psychology, University of California, Santa Barbara, California 93106-9660. Electronic mail may be sent via Internet to fukusima@usp.br or loomis@psych.ucsb.edu. distance is not linked tightly to that of exocentric distance (see also Gogel, 1977), our focus here is on the former.

It generally is accepted that when visual cues to distance are reduced greatly, egocentric distance is misperceived (e.g., Baird, 1970; Da Silva, 1985; Foley, 1977, 1980; Foley \& Held, 1972; Gogel, 1974; Holway \& Boring, 1941; Künnapas, 1968; Philbeck \& Loomis, 1997; Sedgwick, 1986). Under "full-cue" conditions, in which a stimulus-rich environment is viewed under good illumination, however, there is little agreement about whether perception is accurate, mainly because of the diversity of findings stemming from different experimental methods. With respect to egocentric distance, much of the research conducted under full-cue conditions suggests that perceived distance is nearly linear in physical distance and appropriately scaled, at least for targets within $20 \mathrm{~m}$ (e.g., verbal reports, Da Silva, 1985; Sedgwick, 1986; Teghtsoonian \& Teghtsoonian, 1969, 1970; blind walking to previewed targets, Corlett, Patla, \& Williams, 1985; Elliott, 1986, 1987; Elliott, Jones, \& Gray, 1990; Loomis, Da Silva, Fujita, \& Fukusima, 1992; Rieser, Ashmead, Talor, \& Youngquist, 1990; Steenhuis \& Goodale, 1988; Thomson, 1983); in those studies, power functions with exponents close to 1.0 were obtained. The results of other research under the same viewing conditions and over the same physical distances suggest a compressive nonlinearity between physical and perceived egocentric distance (i.e., the method of equal appearing intervals; Gilinsky, 1951; Harway, 1963); here, the power function exponents were $0.7-0.8$.

In earlier work, Loomis et al. (1992) noted that the linearity and accuracy of the mean indicated distances obtained with open-loop walking to previewed targets might be explicable in a way other than that perception of distance is linear and without systematic error. One potential explanation is that if the mapping between perceived egocentric distance and physical distance is an unchanging nonlinear 
function of physical distance under full-cue conditions, observers might learn to calibrate their walking to be accurate in spite of perceptual error. However, there are two reasons to doubt this explanation. First, few if any observers ever walk blindly to previewed targets more than $5 \mathrm{~m}$ away, so there should be little opportunity for this putative correction of the perceptual errors associated with distances beyond $5 \mathrm{~m}$. Second, and more important, Loomis et al. (1992) presented evidence from a novel triangulation task that egocentric distance is perceived without systematic error out to a distance of at least $5.7 \mathrm{~m}$, the largest distance studied.

In this "triangulation-by-pointing" task, observers viewed a target on the ground from a stationary location and, with eyes closed, attempted to walk along straight paths that passed by the target while attempting to point at the unseen target (see Figure 1C). The pointing directions of the arm should converge on the perceived (not physical) target location as initially viewed from the origin of locomotion. The azimuth of the arm, averaged over observers and replications, exhibited little systematic error for three different paths varying in closest approach to the target. As we argue, their successful performance of this triangulation task is strong evidence that observers were indeed perceiving the target distances correctly from the origin of locomotion. The current research extends the use of this method to much larger target distances.

As a general means of measuring distance (physical or perceptual), triangulation relies on the measurement of direction to a target from at least two distinct locations in space (see Figure 1A). If the two directions (angles) are measured without error and the base separating the two locations is known, the position of the target can be computed with respect to the base, thus giving distance $D_{i}$ to either of the endpoints (see Figure 1A). An example of triangulation is the use of binocular convergence in the perception of distance; sensing of the vergences of the two eyes, both fixated on a near target, is used by the visual system to estimate the target's egocentric distance (Foley, $1980)$. Gogel $(1974,1982)$ was probably the first to develop a triangulation method for measuring perceived egocentric distance (see also Gogel, 1990, 1993; Gogel, Loomis, Newman, \& Sharkey, 1985). His method, depicted in Figure 1B, involves movement of the observer's head and the observer's judgment of any apparent movement of the target that there might be. In the example shown in the figure, if the observer views a stationary target within a frontoparallel plane that is a distance $D_{P}$ away but it is perceived with a distance $D^{\prime}$, and the observer's head moves laterally through a distance $K$ (assumed here to be equal to the perceived displacement $K^{\prime}$ ), the observer will perceive an apparent motion equal to $W^{\prime}$. The observer's judged motion $W^{\prime}$ then can be used to calculate $D^{\prime}$ using the following expression:

$$
D^{\prime}=D_{P}\left(K^{\prime}-W^{\prime}\right) / K^{\prime}
$$

(a)

(b)
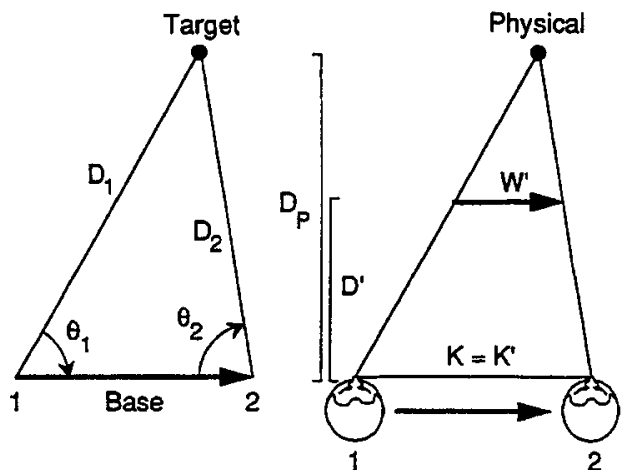

(c)

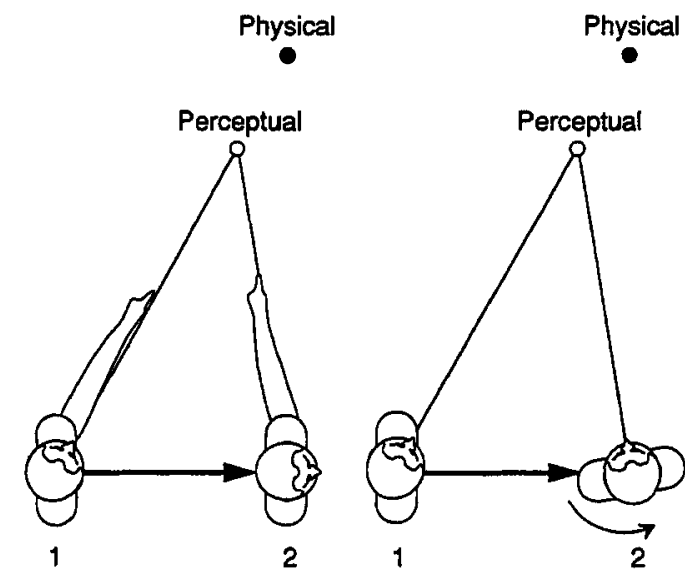

Figure 1. a: Triangulation as a general method for measuring the coordinates of a target. If angles $\theta_{1}$ and $\theta_{2}$ and the triangulation base are known, distances $D_{1}$ and $D_{2}$ can be computed. b: Gogel's $(1990,1993)$ head motion procedure. If the perceived directions to the target before and after head translation are equal to the physical directions, if the perceived head displacement is equal to the physical displacement, and if the target appears stationary, its perceived location is equal to its physical location. If it appears at some other distance than its physical location, it will appear to move through a displacement $W^{\prime}$ at the same time the head is displaced through $K$. c: Triangulation by pointing. If the observer points to the azimuths of a physical target before and after walking without vision, the indicated azimuths can be used to triangulate the initially perceived and updated target location. $\mathrm{d}$ : Triangulation by walking. If the observer faces the direction of a physical target before and after walking without vision, the indicated headings can be used to triangulate the initially perceived and updated target location. 
So, for example, when $W^{\prime}$ is judged to be zero, $D^{\prime}$ is computed to be equal to $D_{P}$; also, when $W^{\prime}$ is judged equal to $-K^{\prime}$ (the same magnitude but in a direction opposite to that of the head motion), $D^{\prime}$ is computed to be twice $D_{p}$.

A weakness that all triangulation methods have is the decline in measurement precision with target distance; this decline results from measurement noise regardless of whether it originates in the physical measurement, in perception, or in the judgmental process. For a variety of reasons, Gogel $(1990,1993)$ limited lateral head motions in his procedure to around $50 \mathrm{~cm}$. Consequently, the method has yet to be adapted to the measurement of large outdoor distances.

Our concern here was with two triangulation methods that make use of visually "open-loop" (visually directed) action. The first of these, triangulation by pointing, has been mentioned (see Figure 1C). As used in our research, the observer views the target from Position 1 and points with the arm. The observer then walks without vision to Position 2 while pointing continuously to the imaginally updated location of the target. The measured direction of the arm at Position 2 is used to measure the perceived and subsequently updated target location. The other, "triangulation by walking" (see Figure 1D), involves viewing a target from Position 1 and then closing the eyes and walking along a straight path until instructed to turn, at Position 2, to face and possibly continue on toward the target. The terminal heading or course $e^{1}$ of the observer is assumed to be in the direction of the initially perceived and imaginally updated target location. Whereas Gogel's $(1990,1993)$ method relies on a judgment of apparent target displacement during lateral head movement, our two methods rely on the updating of a mental representation during observer locomotion. Although the reliance on mental imagery might appear to be a disadvantage, the method has the appeal of being natural for the observer, even for translations of 5-10 m; indeed, it is such a natural task for targets within several meters that one is not apt to appreciate the complexity of the underlying process. The ease with which people do imaginal updating suggests that it plays an important role in the link between perception and action; one such role might be to allow a moving observer to continue directing his or her action toward a target that is temporarily occluded by another object, such as a wall. Indeed, others have recognized the importance of imaginal updating and have devoted considerable research investigating its properties (Böök \& Gärling, 1981; Corlett, 1986; Corlett, Byblow, \& Taylor, 1990; Corlett \& Patla, 1987; Corlett et al., 1985; Elliott, 1986, 1987; Elliott et al., 1990; Laurent \& Cavallo, 1985; Laurent \& Thomson, 1988; Loarer \& Savoyant, 1991; Potegal, 1971, 1972; Presson \& Montello, 1994; Rieser, 1989; Rieser, Guth, \& Hill, 1986; Rieser, Pick, Ashmead, \& Garing, 1995; Thomson, 1980, 1983). In particular, Böök and Gärling (1981) used a task similar to our triangulationby-pointing procedure, except that they obtained verbal reports of distance rather than pointing; their interest was in elucidating the imaginal updating process. In much of this literature on imaginal updating, the idea of triangulation is implicit, but we are unaware of any work undertaken with the intent of using imaginal updating and triangulation to measure perceived target distance.

Before discussing the experiments, we elaborate on the various subprocesses that must be involved in the execution of visually directed action (Loomis et al., 1992, p. 918). To start with, the observer's perception of the target is converted into some memorial representation of the target. Then, as locomotion proceeds with eyes closed, the observer perceives his or her self-velocity and integrates it to obtain displacement from the origin of locomotion; this process of updating one's position relative to the origin is referred to as "path integration" (see Etienne, 1992; Gallistel, 1990; Israel \& Berthoz, 1992; Loomis et al., 1993; Mittelstaedt \& Mittelstaedt, 1982; Rieser \& Garing, 1994). Also, while updating self-position, the observer must update the perceived (and now imagined) target location. Finally, the observer must indicate the position of the updated target location, either by pointing at it, facing in its direction, walking in its direction, or stopping at its location. Systematic error and random noise within any subprocess will contribute to errors in performance of the task. Nearly perfect performance of the task conceivably could result from cancellation of opposing errors in the subprocesses, but such performance is much more likely to be a consequence of the near absence of error and noise in each of the subprocesses.

\section{Experiment 1}

The goals of this experiment were to determine whether triangulation by pointing is a useful method for measuring perceived egocentric distance for physical distances larger than those studied in Experiment 3 of Loomis et al. (1992) and to assess how accurately egocentric distance is perceived. We used two conditions. In the no-vision condition, the observer viewed the target and then attempted, with eyes closed, to point continuously toward it while walking on a straight path past it. In the vision condition, which was a control condition, the observer pointed continuously toward the target with eyes open while walking. The purpose of the vision condition was to indicate the accuracy of the observer's pointing and of our physical measurements of pointing response. This task depends on neither the observer's perception of target distance nor his or her imaginal updating of the target. If pointing and our measurements of it are accurate, the triangulated location and actual location of the target should be identical, thus giving a triangulated target distance from the origin close to or equal to that of the physical distance.

\footnotetext{
${ }^{1}$ The term heading refers to facing direction, whereas the term course refers to the direction of movement. During terrestrial travel, heading and course are generally the same or nearly so, but they can be much different during skidding, sidestepping, and crabbing into the wind (e.g., as in boating and flying).
} 


\section{Method}

Observers. Nine students (5 men and 4 women), aged 19-37 years, from the University of California, Santa Barbara (UCSB), were paid observers in this experiment. All observers were righthanded. As noted in the Results section, data from 1 observer were omitted from the analysis.

Materials and apparatus. The experiment was carried out in a flat and grassy open field $(25 \times 50 \mathrm{~m})$ at the UCSB campus. Buildings, trees, and bushes were visible in most directions well beyond the perimeter of the field. Along the two longer sides were straight sidewalks. This part of campus was not heavily trafficked, and passersby generally remained outside the field. In this experiment and all that follow, the weather was dry and visibility was excellent.

The target consisted of a tripod with a white ball $6 \mathrm{~cm}$ in diameter mounted on top; the tripod was adjusted so that the ball was at the observer's eye level. The target was placed at any of eight locations on the field (see Figure 2), which were specified in terms of their distances and azimuths from the origin, which was located on the sidewalk. The azimuths were measured clockwise in relation to the edge of the sidewalk. The distances and azimuths of the eight target locations are listed in Table 1. The tripod and ball were clearly visible at all target locations.

A $1.20-\mathrm{m}$-high turnstile with a rotating horizontal bar $4 \mathrm{~m}$ long was placed on the sidewalk at a distance of $4.7 \mathrm{~m}$ from the origin (see Figure 3). This was used to stop the observer's locomotion. An electronic compass (KVH [Middletown, RI] model Azimuth 100 ) was used to measure the direction of the observer's arm at the beginning and end of each trial. This electronic compass was mounted firmly on the right upper arm using a blood pressure cuff. The compass was gimbaled to provide accurate readings of azimuth even with tilting. It was powered by a $12-\mathrm{V}$ battery, which was carried in a waist pack. With calibration using a large protractor, the compass was accurate to within the $1^{\circ}$ display precision.

Procedure. Before observer testing, the experimenter calibrated the electronic compass and marked the target locations on the ground with golf tees, which were invisible from the origin of locomotion. At the start of each trial, the observer stood at the origin of locomotion with body and head facing the turnstile (see

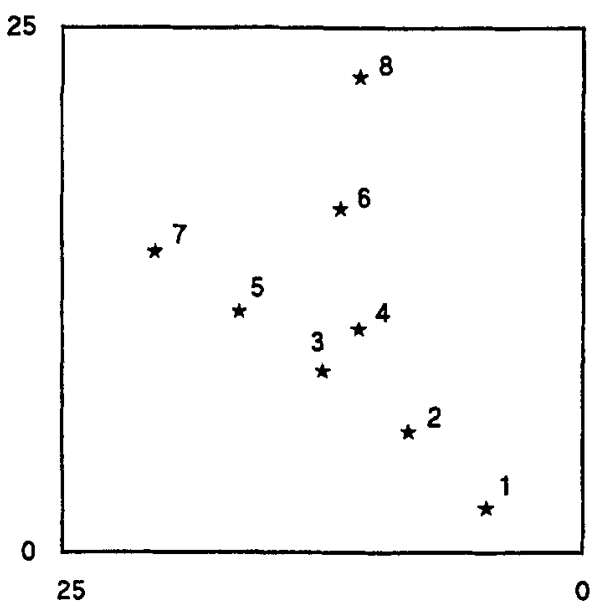

Figure 2. The locations of the targets used in Experiments 1 and 2. The origin of locomotion is at the lower right-hand comer (coordinates are marked 0,0 ). The workspace dimensions are in meters.
Table 1

Initial Distances and Azimuths of Targets Used in Experiments 1 and 2

\begin{tabular}{ccc}
\hline Target no. & Distance $(\mathrm{m})$ & Azimuth (degrees) \\
\hline 1 & 5 & 25 \\
2 & 10 & 35 \\
3 & 15 & 35 \\
4 & 15 & 45 \\
5 & 20 & 35 \\
6 & 20 & 55 \\
7 & 25 & 35 \\
8 & 25 & 65 \\
\hline
\end{tabular}

Figure 3). When instructed, he or she then turned his or her head to face and view the target binocularly. He or she then pointed the arm and hand toward the target, and the experimenter recorded the azimuth of the arm. On no-vision trials, the observer then began walking, with eyes closed, toward the tumstile while continuing to point toward the target. (The rope depicted in the figure was not used in this experiment.) On reaching and feeling contact with the rotating bar, the observer stopped (with a slight overshoot) and then continued to point toward the target until the experimenter had recorded the azimuth of the arm. The observer then turned away from the field, opened his or her eyes and returned to the origin to begin another trial; during the return, the observer was not permitted to look in the direction of the freld. A trial in the vision condition was run in precisely the same fashion, except that the observer continued to look at the target during the traverse and was able to stop just short of the turnstile using peripheral vision.

The observer responded to each target location seven times, first in the no-vision condition and then in the vision condition. In each, the entire set of target locations was presented in seven blocks, within each of which the order of target locations was randomized. Before the experiment proper, the observer practiced the no-vision task two times with the target placed at a random location; no feedback about performance was provided other than to encourage observers to walk quickly and confidently. Also, to obtain the compass direction of the sidewalk before starting the experiment, the observer pointed four times to the target when it was positioned straight ahead on the sidewalk $5 \mathrm{~m}$ away. The average of these measurements was used to establish the direction of the locomotion path, with respect to which the internal angles of the triangle were computed.

\section{Results}

Because the turnstile was located on the sidewalk $4.7 \mathrm{~m}$ from the origin, observers pointing without vision tended to walk around $30 \mathrm{~cm}$ after reaching the turnstile, thus walking a total distance of $5.0 \mathrm{~m}$, the distance we had intended to use. When the pointing was carried out with continuous vision, observers stopped right at the turnstile. Thus, we used distances of $4.7 \mathrm{~m}$ and $5.0 \mathrm{~m}$ in calculating the triangulated distances for pointing with vision and without vision, respectively.

Because the data of one male observer were highly discrepant from those of the other observers, with the pointing converging in some cases to a location opposite that of the target, we dropped his data from the analysis.

To minimize the effects of noise in the triangulation measurement, we computed the means of the seven initial 


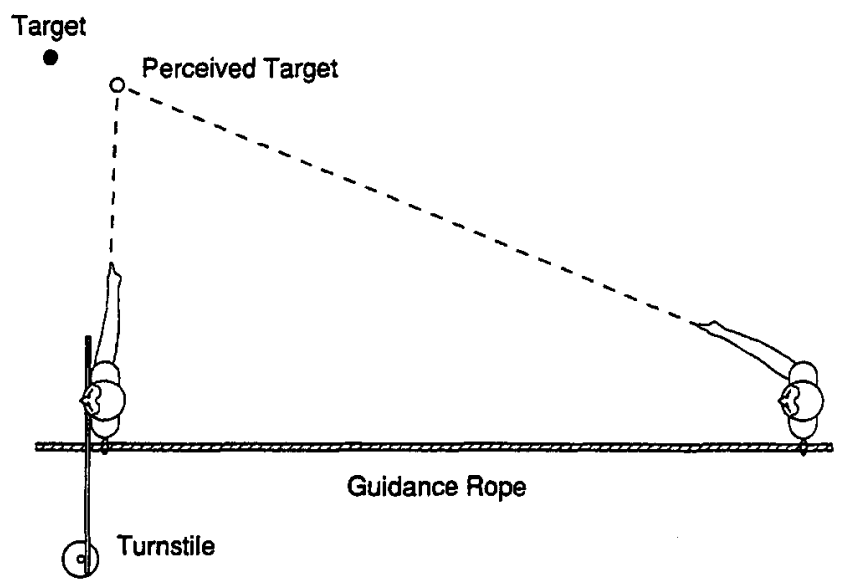

Figure 3. Experimental setup used in Experiments 1 and 2. The observer stood at the origin (right) and, with eyes open, pointed toward the physical target; the perceived target location is depicted here as being closer. An electronic compass mounted on the upper arm was used to measure the pointing azimuth. The observer then closed his or her eyes and walked toward the turnstile while continuing to point toward the target. The terminal pointing azimuth was measured after the observer stopped at the turnstile.

azimuths and seven terminal azimuths for each target and observer. These two means then were used to compute, by triangulation, the indicated distance, $D_{i}$, for each target and observer with respect to the origin:

$$
D_{i}=W \sin \left(\theta_{2}\right) / \sin \left(\theta_{1}+\theta_{2}\right),
$$

where $\theta_{1}$ was the mean initial azimuth of the arm, $\theta_{2}$ was $180^{\circ}$ minus the mean terminal azimuth, and $W$ was the walked distance (the triangulation base). The indicated distances for each observer were used to compute the means for each target in each of the two conditions.

For both conditions, the target locations equivalent in distance from the origin but differing in azimuth (i.e., Target
Pairs 3 and 4, 5 and 6, and 7 and 8) had mean indicated distances that were highly similar. In the no-vision condition, Targets 3,5 , and 7 had mean indicated distances of 14.0, 15.6, and 18.9, respectively, whereas Targets 4,6 , and $8 \mathrm{had}$ mean indicated distances of $13.5,15.2$, and 18.4, respectively. In the vision condition, these values were 15.0 (Target 3), 19.8 (Target 5), 29.7 (Target 7), 14.8 (Target 4), 20.2 (Target 6), and 25.5 (Target 8). Accordingly, we collapsed across the two locations in each of these pairs in computing the means and standard errors of the mean shown in Figures $4 \mathrm{~A}$ and $4 \mathrm{~B}$ for the no-vision and vision conditions, respectively. Thus, data points for the shorter distances of 5 and $10 \mathrm{~m}$ were based on 8 scores each, whereas those for the distances of 15,20 , and $25 \mathrm{~m}$ were based on 16 scores each.

A repeated measures two-way analysis of variance (ANOVA; Vision Availability $\times$ Target Distance) performed on the responses showed a significant main effect of target distance, $F(4,28)=110.6, p<.001, M S E=6.47$, and a significant Distance $\times$ Availability interaction, $F(4$, $28)=11.1, p<.001, M S E=6.85$. The exponents of the best-fitting power function for the data plotted in Figure 4 were 0.66 for the no-vision condition and 1.04 for the vision condition.

\section{Discussion}

$D_{i}$ in the control (vision) condition did not depend on the observer's perception of distance or his or her ability to update the location of the internally represented target during locomotion. $D_{i}$ depended only on the observer's ability to point toward the target and on the accuracy with which we were able to measure this pointing direction. The indicated distances in Figure 4B were practically the same as the physical distances, indicating both that observers pointed accurately to seen targets and that our measurement of direction was highly accurate, at least when averaging over multiple trials.
(A)

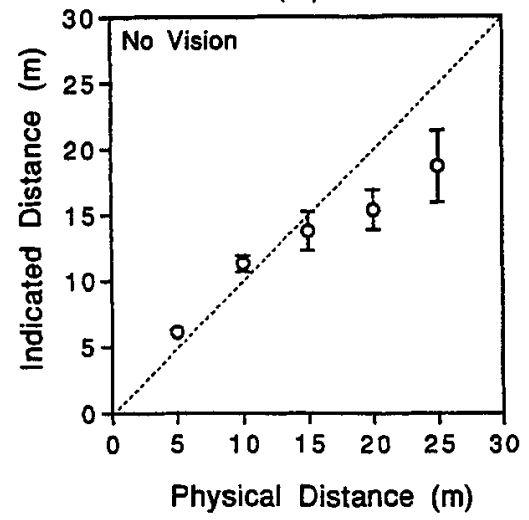

(B)

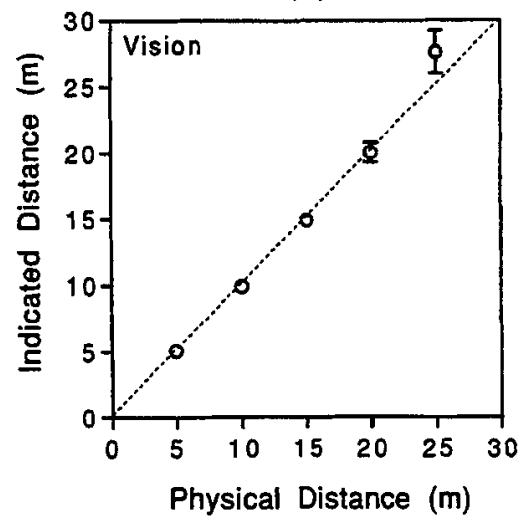

Figure 4. The results of Experiment 1. A: The mean indicated distances of the targets obtained from triangulation by pointing in the no-vision condition. B: The mean indicated distances of the targets obtained from the pointing response when vision was available continuously. In both panels, the error bars represent 1 SEM. 
In the no-vision condition, $D_{i}$ represented the perceived egocentric distance of the target from the origin under the assumptions that (a) observers correctly perceived their self-motion, (b) observers correctly updated the internally represented target location during locomotion, and (c) observers correctly pointed to the perceived and updated target location. The results of Experiment 1 indicate that perceived egocentric distance as measured by triangulation by pointing is accurate up to $15 \mathrm{~m}$. Beyond this, a systematic underestimation of perceived distance appears to be the result.

\section{Experiment 2}

Because of a concern that triangulation by pointing is too noisy a procedure for measuring the perceived distances of far targets when a locomotion base of only $5 \mathrm{~m}$ is used, we conducted Experiment 2 to determine whether changing the base would yield different values of indicated distance. Hence, observers performed the same tasks as in Experiment 1 , but they did so while walking a distance of either 5 or $10 \mathrm{~m}$.

\section{Method}

Observers. Eight right-handed students ( 5 men and 3 women) from UCSB, none of whom had participated in Experiment 1, served as paid observers in this experiment. All observers had normal visual acuity with or without corrective lenses in both eyes and normal stereoscopic depth perception as measured by a Keystone (Meadville, PA) Orthoscope. They were aged 19-23 years.

Materials and apparatus. This experiment was conducted in the same field as in Experiment 1, and the tripod, turnstile, and electronic compass were the same. This time, however, six rather than eight locations were used; the two most distant targets in Figure 2 were not used. In addition, the turnstile was placed at either of two locations on the sidewalk so that the observer walked distances of either 5 or $10 \mathrm{~m}$ from the origin. To prevent veering while observers walked without vision, we strung a 12-m nylon rope between two white plastic posts, each of which was $1.20 \mathrm{~m}$ in height, and positioned it to the left side of the observer (see Figure 3). The rope passed through a metal ring that was attached to the left side of the waist pack as the observer walked toward the turnstile.

Procedure. The procedure was the same as that used in Experiment 1 , except for the following changes. In this experiment the observer wore the ring attached to the rope on the left side. Also, the observer had to walk either 5 or $10 \mathrm{~m}$ toward the turnstile while pointing at the target. This time, the position of the turnstile was adjusted so that each observer walked nearly 5 or $10 \mathrm{~m}$ in both the vision and no-vision conditions. The observer performed four trials for each of the target distances and walking distances in both the vision and no-vision conditions. These trials were blocked by walking distance and condition. First, all the no-vision trials were run, and there were eight blocks in each of which the six target locations were presented; the order of presentation of blocks for the walking distance and the order of presentation of target locations within blocks were randomized. All the vision trials then were run.

Before the experiment proper, the observer practiced the novision task two times with the target placed at a random location; no feedback about performance was provided other than to encourage observers to walk quickly and confidently.

\section{Results}

As before, the four initial and terminal azimuths to each target by each observer in each condition were averaged to obtain mean initial and terminal azimuths. These then were used to compute an indicated distance for each target and observer using Equation 2, and the resulting values were averaged to obtain mean indicated distances for the different targets in each of the four conditions. As before, we collapsed across the target pairs equal in distance but differing in azimuth and then computed the means and standard errors of Figure 5. Accordingly, the data points for distances of 5 and $10 \mathrm{~m}$ were based on 8 scores and those for 15 and $20 \mathrm{~m}$ were based on 16 scores ( 8 observers $\times 2$ locations).

A repeated measures three-way ANOVA (Vision Availability $\times$ Target Distance $\times$ Walking Distance) performed on the responses showed a significant main effect of target distance, $F(3,21)=123.6, p<.001, M S E=9.86$, and a significant Distance $\times$ Availability interaction, $F(3,21)=$ $7.5, p<.001, M S E=10.48$. The exponents of the bestfitting power function for the data plotted in Figure 5 were 0.74 for $5 \mathrm{~m}$, no vision; 0.74 for $10 \mathrm{~m}$, no vision; 1.09 for $5 \mathrm{~m}$, vision; and 1.04 for $10 \mathrm{~m}$, vision.

\section{Discussion}

The results for the 5-m base were essentially the same as those for Experiment 1. (In Experiment 2 we did not use $25-\mathrm{m}$ targets). For distances out to $15 \mathrm{~m}$, the vision and no-vision results were highly similar, except for the much larger interobserver variability at $15 \mathrm{~m}$. The results indicate that perceived egocentric distance, averaged over observers, was highly accurate out to $15 \mathrm{~m}$, with clear underestimation of distance beyond that.

Increasing the triangulation base from 5 to $10 \mathrm{~m}$ increased the precision of measurement at all target distances except $5 \mathrm{~m}$, as shown by the decreased interobserver variability in both the vision and no-vision conditions. The near concordance of the indicated distances for vision and no vision out to $15 \mathrm{~m}$ suggests that egocentric distance is perceived accurately over this range. The fact that the indicated distances for $20 \mathrm{~m}$ were substantially lower in the no-vision condition again suggests underestimation of this distance.

\section{Experiment 3}

Informal observations persuaded us that there might be a better way to triangulate the location of a previously viewed target than the pointing method used in Experiments 1 and 2. Introspectively, we experienced less confidence in pointing to a previously viewed target than in turning to face it. Accordingly, we developed a second triangulation method that involved viewing the target, closing the eyes, walking along a path oblique to the target, and then turning to face 

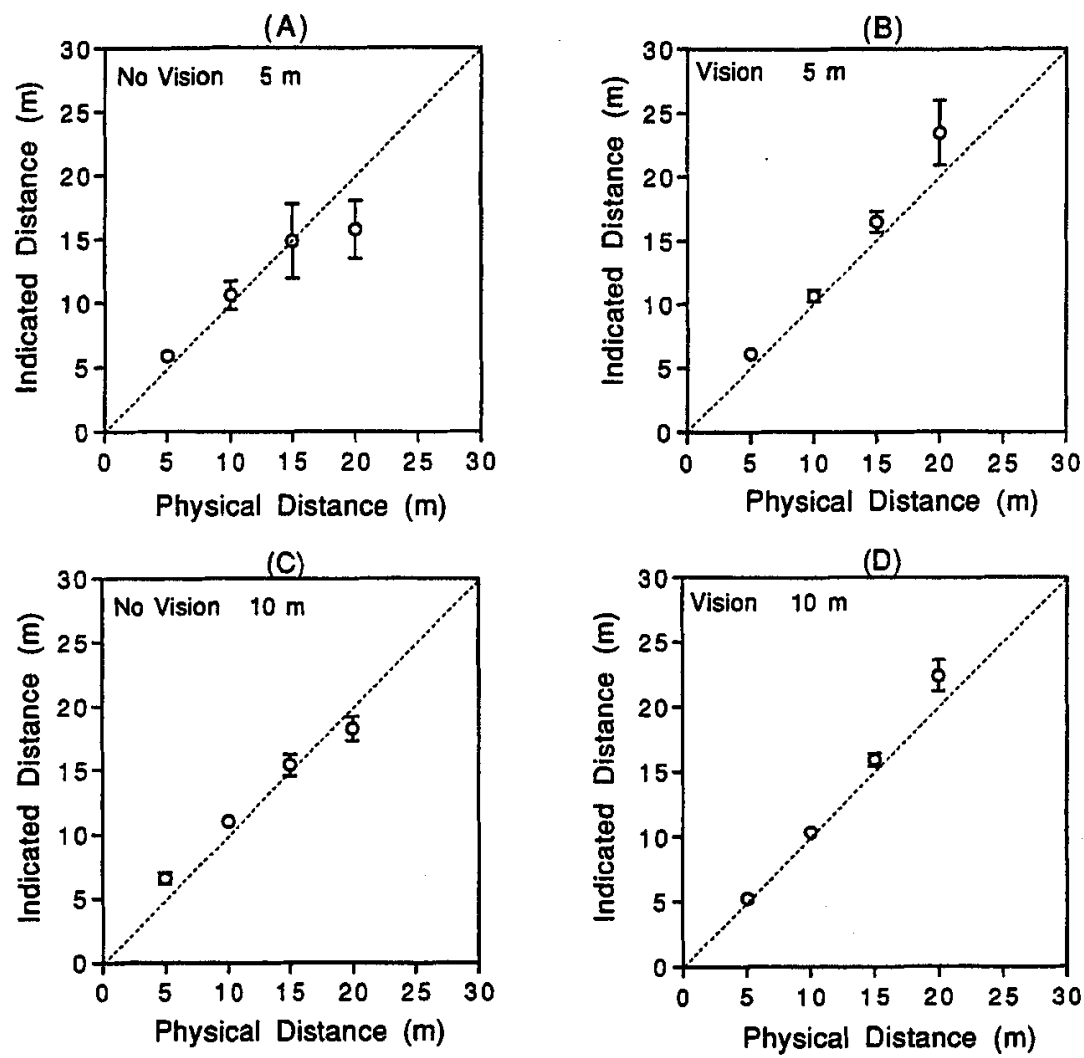

Figure 5. The results of Experiment 2. A: The mean indicated distances of the targets obtained from triangulation by pointing in the no-vision condition; the walking distance used as the triangulation base was $5 \mathrm{~m}$. B: The mean indicated distances of the targets obtained from the pointing response when vision was available continuously; the triangulation base was $5 \mathrm{~m}$. C: The mean indicated distances of the targets obtained from triangulation by pointing in the no-vision condition; the triangulation base was $10 \mathrm{~m}$. D: The mean indicated distances of the targets obtained from the pointing response when vision was available continuously; the triangulation base was $10 \mathrm{~m}$. In all four panels, the error bars represent $1 S E M$.

the imaginally updated target (see Figure 1D). With such a method, one can use the terminal heading, along with the initial target direction, to triangulate the perceived and updated target location. In a variant of this triangulation method, one could have the observer continue walking after the turn in the direction of the target. In this case, one uses the terminal course in place of the terminal heading in triangulating the perceived and updated location of the target. We thought that walking beyond the turn point was slightly more natural and thus opted for this variant in Experiment 3.

\section{Method}

Observers. Twenty UCSB student (14 men and 6 women) participated as paid observers. They were aged $18-36$ years. All had 20/20 visual acuity and normal stereoacuity (measured with the Keystone Orthoscope) with or without correction. All observers were regularly involved in some form of regular athletic activity, such as jogging, tennis, or intramural sports.

Materials and apparatus. The experiment was carried out in a flat, open, and grassy field $25 \times 50 \mathrm{~m}$. The observer's field of view included trees and bushes beyond the perimeter of the field. The five target locations in Figure 6 were marked with golf tees, which were invisible from the origin of locomotion. These locations were $8,12,16,20$, and $24 \mathrm{~m}$ from the origin. Two $10-\mathrm{m}$ oblique pathways from the origin (one to the right and one to the left) were constructed with angles of $32^{\circ}$ with respect to a reference line (see Figure 6), which coincided with a straight sidewalk at the edge of the field. The terminal points of these two pathways were marked on the ground with white spheres $6 \mathrm{~cm}$ in diameter. Two turn locations were marked on each pathway, one $4 \mathrm{~m}$ from the origin and the other $6 \mathrm{~m}$ from the origin. The golf tees marking these turn locations were invisible from the origin.

We used trilateration to measure the Cartesian coordinates of locations in the field. To trilaterate a location, we made distance measurements of the location from two fixed positions located off to both sides of the origin in Figure 6. For these distance measurements, we used the Sonin (Brewster, NY) 250 ultrasonic distance-measuring system, which has a range of $80 \mathrm{~m}$. It consists of two units: an ultrasonic transmitter and an ultrasonic receiver, the latter of which also does the measurement; the two also communicate by infrared light. The measuring unit sends an infrared signal to the transmitter and receives an ultrasonic pulse in return. The return time through air is used to compute distance 


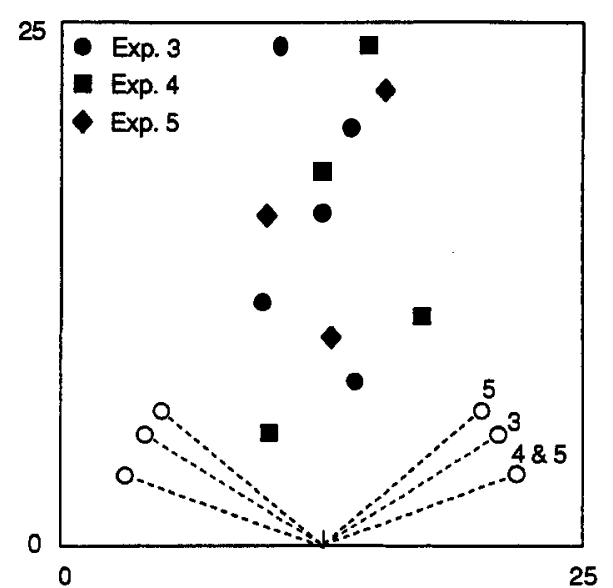

Figure 6. The locations of the targets used in Experiments 3-5. The origin of locomotion is at the lower center. The workspace dimensions are in meters. Exp. = experiment.

between the two. We actually used two infrared transmitters that were fixed at the measuring locations throughout the experiment.

The target consisted of a tripod with the Sonin ultrasonic transmitter, which is a yellow rectangular object $7 \mathrm{~cm}$ wide and $12 \mathrm{~cm}$ high mounted on top at a height of $93 \mathrm{~cm}$. Both the tripod and yellow object were clearly visible at all locations used in the experiment.

A heavy, 2-m-long steel chain was attached to the observer's belt in the back and trailed behind the observer. We used this to measure the observer's direction of travel.

Procedure. Before the running of each observer, the Sonin distance-measuring units were calibrated against a metal tape measure. Because earlier work had shown that the measurement was almost perfectly linear in distance (with zero intercept), our calibration procedure involved only establishing the scale value, which tended to vary with temperature and humidity. To establish these scale values, we used distances of 5,10 , and $25 \mathrm{~m}$. The resulting distance measurement was accurate to $2 \mathrm{~cm}$.

On each trial, the observer stood at the origin of locomotion and faced away from the field while the target was being positioned at one of the five locations in Figure 7 . The observer then turned around so that he or she faced directly toward the field and viewed the target binocularly. When ready, the observer then turned toward the left or right oblique path, as indicated by the white ball at its terminus, and then began walking with eyes closed along the path. When the observer arrived at either the 4- or 6-m turn point (see Figure 7), one of the experimenters gave a verbal command ("turn") so that the observer would turn toward the imagined target location. In response, the observer turned and continued walking for several meters. While the observer stood with his or her eyes closed, an experimenter then marked two positions along the chain, separated by about $1 \mathrm{~m}$, with golf tees. The observer then was led with eyes closed back to the origin along a circuitous route and then turned to face the target again. This time, the observer walked along the oblique path in the other direction. Once again, two marks were made in the field. After the observer was led back to the origin, the two experimenters used the ultrasonic units to measure the distances of the four golf tees. Random assignment determined which of the two oblique paths (to the left or right) was to be used on the first half of the trial.

There were 20 trials for each observer: 4 trials for each of the five target locations; 2 of the 4 trials involved a turn at the 4 -m point and 2 at the $6-\mathrm{m}$ point. The trials for combinations of distance and turn distance were randomized completely, and the observer never knew in advance when the command to turn would be given. This feature of the experiment is important because, if the observer also could have known the turn point while viewing the target, he or she possibly could have used this information to plan the terminal course in advance. Thomson (1983) used a similar manipulation in his experiments on visually directed walking to rule out the possibility that observers were preprogramming the entire response to a target before executing the response.

Before the experiment proper, the observer practiced the task just one time with the target placed at a random location. No feedback about performance was provided other than to encourage observers to walk quickly and confidently.

\section{Results and Discussion}

Each trial involving a walk to the right and a walk to the left resulted in an estimate of the perceived target location. This estimate was obtained in the following way: The two locations marked by the golf tees and representing the terminal course on the left were determined by trilaterating the measured distances with respect to the two fixed measurement locations; these locations then were used to con-

Target $\bullet$

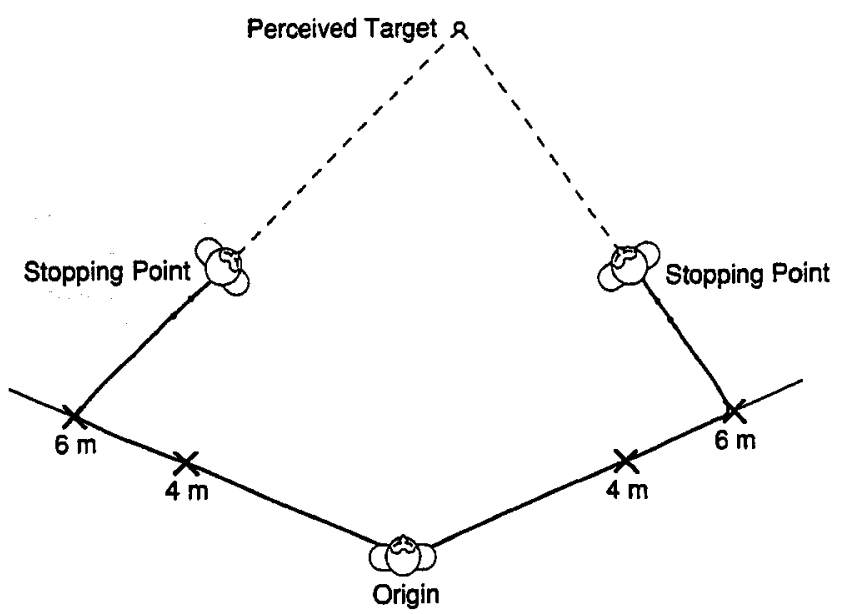

Figure 7. Experimental setup used in Experiments 3-5. The observer stood at the origin and viewed the physical target; in Experiment 3, the observer's body faced forward during viewing, but in Experiments 4 and 5, the observer's body was angled toward one of the walking paths. When ready, the observer closed his or her eyes and walked along either of the left or right walking paths and, on command, turned and walked several meters toward the perceived and imaginally updated target. In Experiment 3, the turn points were either 4 or $6 \mathrm{~m}$ from the origin, as shown; in Experiment 4 , a single turn point at $5 \mathrm{~m}$ was used, and in Experiment 5 , a single turn point of $6 \mathrm{~m}$ was used. The terminal course was measured by marking two locations on the ground aligned with a heavy chain that the observer dragged behind. These marked locations were measured subsequently using trilateration. The intersection of the course lines for responses made to the right and left indicated the location of the perceived and imaginally updated target. 
struct a line representing the observer's path toward the imaginally updated target. Similarly, the two marked locations representing the terminal course on the right were used to construct the path line for the right. We then triangulated the perceived and imaginally updated target location-the intersection of the two path lines defined this location, under the assumption that imaginal updating and perception of self-motion (including the turn) were done without error.

Because the positions of the golf tees varied from trial to trial even for the same target and turn point, it was not possible to average the terminal courses for the two trials for each combination of target distance and turn distance. Accordingly, the estimates of target location were noisier than were those obtained with the pointing method, in which averaging of initial and terminal azimuths was done. The noisiness of the data is problematic because there is some bias associated with the method. An error in measuring terminal course that is toward field center causes a larger error in estimating the perceived target location than does the same angular error away from field center; the result is a bias toward overestimating perceived target distance. One way to evaluate the seriousness of this bias is to use two walking bases and observe the effect on indicated distance; a larger base ought to increase the precision of measurement and reduce the degree of bias. Accordingly, we computed the estimated perceived target location with both the large walking base and the small walking base.

Each of the two estimated perceived target locations obtained for each observer and for each combination of target distance and tum distance (walking base) resulted in a single estimate of perceived target distance. These two estimates were averaged to obtain a single score for each observer and for each combination of turn distance and target distance. These scores then were used to compute the means and standard errors of the mean given in Figure 8. Hence, the standard errors reflect pure interobserver variability.

The results in Figure 8 indicate that increasing the walk- ing distance before the turn from 4 to $6 \mathrm{~m}$ (which increases the triangulation base) does reduce slightly the interobserver variability. Furthermore, the indicated distances for 12,16 , and $20 \mathrm{~m}$ appeared to have been reduced slightly by the change in turn distance, whereas those for 10 and $24 \mathrm{~m}$ showed essentially no change. To determine whether there would be any statistically reliable effect of changing the triangulation base, we performed a repeated measures twoway ANOVA (Turn Distance $\times$ Target Distance). The only significant effect was the main effect of target distance, $F(4$, $76)=112.03, p<.001, M S E=13.69$. The exponents for the best-fitting power functions also indicated little effect of turn distance: 0.94 for the turn at $4 \mathrm{~m}$ and 0.90 for the turn at $6 \mathrm{~m}$.

The finding that there was little if any effect of increasing the triangulation base means that the potential bias toward overestimating the perceived and imaginally updated target location was not evident here.

\section{Experiment 4}

At a public presentation of our work, someone raised the concern that auditory distance cues might contribute to the accurate performance in these tasks. We conducted the following experiment to check on this possibility. The experiment was much like Experiment 3, except that we used two conditions, one in which auditory cues from the environment were available to the observer and one in which they were not.

\section{Method}

Observers. Ten observers (1 woman and 9 men) were drawn from the UCSB population and were paid for participating. Nine observers were aged 19-20 years; the remaining observer was 46 years old. All satisfied the same criteria for visual acuity, stereoacuity, and regular athletic activity used in the previous experiment.
(A)

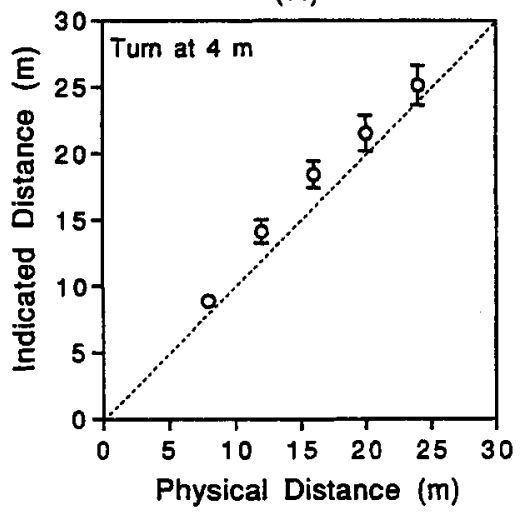

(B)

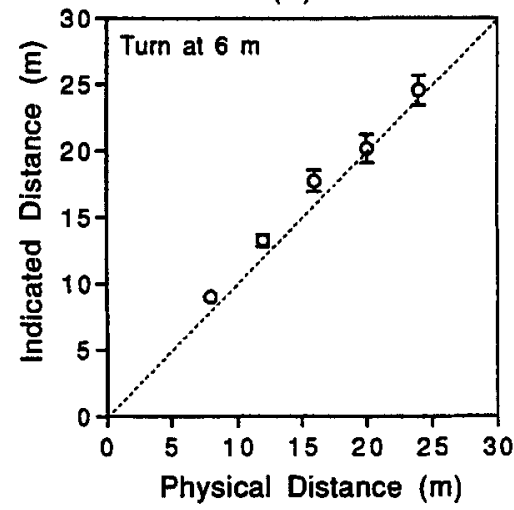

Figure 8. The results of Experiment 3. A: The mean indicated distances of the targets obtained from triangulation by walking in the no-vision condition for the small walking base. B: The mean indicated distances of the targets obtained from triangulation by walking in the no-vision condition for the large walking base. In both panels, the error bars represent 1 SEM. 
Materials and apparatus. Another large, open, grassy field was selected for this experiment. The apparatus for measuring location was the same as that used in the previous experiment. The four target locations used are shown in Figure 6 . Their distances from the origin were $6,12,18$, and $24 \mathrm{~m}$. The left and right walking paths were inclined only $20^{\circ}$ with respect to the measurement line (see Figure 6), and only one turn point, $5 \mathrm{~m}$ from the origin, was used.

To control for possible auditory cues to distance, we used an FM wireless microphone (Telex [Minneapolis, MN] model TW-6) and FM receiver with earphones (Telex model AAR-1), as used by Rieser et al. (1986). The wireless microphone was worn by the experimenter, and the observer wore the receiver and earphones. Because the sound coming from the microphone was the same for both ears and, when properly adjusted in intensity, masked the direct sound, the observer was unable to localize environmental sounds.

Procedure. As in the previous experiment, the ultrasonic distance-measuring equipment was calibrated beforehand. Before conducting trials, we adjusted the intensity of the FM receiver so that observers were unable to localize sounds made by the experimenter or his assistant. In one procedural change from the previous experiment, the turn location always was $5 \mathrm{~m}$ from the origin, although observers had no visual information about this location. Also, instead of having the observer's body facing straight ahead during binocular viewing of the target, the observer aligned his or her body with the instructed pathway (left or right) during viewing of the target, with the head facing the target. This improvement in procedure meant that the observer did not have to reorient the body after viewing the target.

The two conditions (sound cues absent and sound cues present) were represented in two blocks of trials; half the observers received the sound condition first and half received the no-sound condition first. In each block, the observer participated in 3 trials for each of the four target distances, with a trial consisting of a walk to the left and a walk to the right. The direction of the first walk was randomized, as was the order in which the target distances were presented. As in the previous experiment, the observer received just one practice trial prior to the two conditions; no feedback about accuracy of performance was provided.

\section{Results and Discussion}

The data were analyzed as in the preceding experiment. Consequently, we obtained three indicated distances for each target distance and observer within both the sound and no-sound conditions. These three values were averaged to obtain a mean for each observer for each combination of target and condition. In turn, these observer means were used to compute means across observers; these and their corresponding standard errors are shown in Figures 9A (no-sound condition) and 9B (sound condition). The observer means also were subjected to a mixed-measures ANOVA with three variables (Target Distance $\times$ Availability of Sound $\times$ Order of Sound Condition). The only statistically significant effect was the main effect of target distance, $F(3,24)=50.68, p<.001, M S E=22.27$. The exponents of the best-fitting power function for the data plotted in Figure 9 were 0.97 for the no-sound-cue conditions and 0.96 for the sound-cue condition.

The results in Figure 9 and the ANOVA indicate that the availability of environmental sound cues played no role in observers' performance of the walking task. Results also indicate that mean perceived distance was accurate out to and beyond $15 \mathrm{~m}$.

\section{Experiment 5}

The purpose of this last experiment was to compare performance in the triangulation-by-walking task, which demands the perception of distance and imaginal updating, with that in the same task when vision is available continuously, a condition requiring only the ability to walk directly toward a target. In addition, we investigated whether there would be any effect of varying the orientation of the walking path with respect to the targets. We expected none. We also included the visually directed walking task (e.g., Thomson, 1983), in which the observer viewed the target
(A)

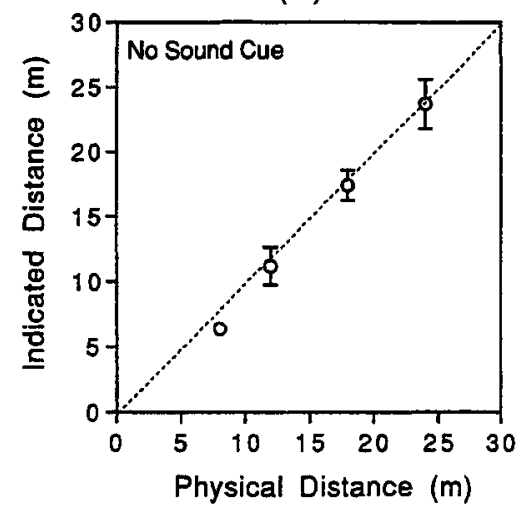

(B)

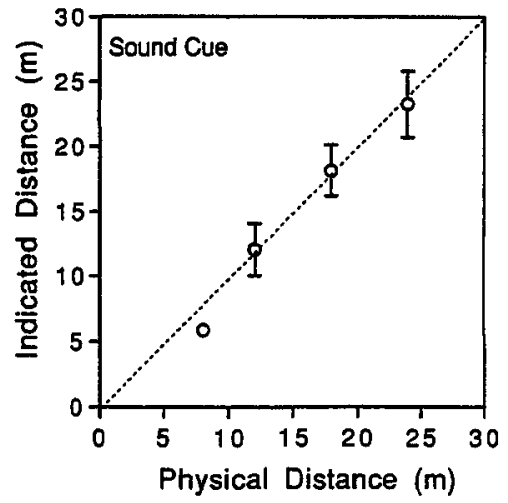

Figure 9. The results of Experiment 4. A: The mean indicated distances of the targets obtained from triangulation by walking when spatial sound cues were eliminated. B: The mean indicated distances of the targets obtained from triangulation by walking when spatial sound cues were available. In both panels, the error bars represent 1 SEM. 
and attempted to walk blindly to its location. We included this task to compare its performance with that of the triangulation task.

\section{Method}

Observers. The 20 observers ( 14 men and 6 women) were drawn from the UCSB population and were paid for their participation. They were aged 18-29 years. All observers met the same criteria for visual acuity, stereoacuity, and regular athletic activity used in the previous two experiments.

Materials and apparatus. The same field used in Experiment 4 was used in this study, and the same distance-measuring and sound-occluding devices were used. Only three targets were used; these had distances of 10,16 , and $22 \mathrm{~m}$ (see Figure 6). This time, we used walking paths that were inclined either 20 or $40^{\circ}$ with respect to the measurement line (see Figure 6); the two paths in either direction were marked at their ends with objects that were easily seen and distinguished. Only one turn point was used for each pathway; this was $6 \mathrm{~m}$ from the origin. Again, observers had no visual information about the turn point on either side.

Procedure. As in the previous experiment, the ultrasonic distance-measuring equipment was calibrated beforehand, and the intensity of the FM receiver was adjusted so that observers were unable to localize sounds made by the experimenters. Sound occlusion was used in all three conditions. Every observer received the three conditions in the order described later.

The procedure on each trial of the no-vision triangulation condition was identical to that used in the previous experiment, except that the observer was told which pathway $\left(20^{\circ}\right.$ or $\left.40^{\circ}\right)$ to travel by reference to the object visible at its terminus. A trial consisted of a response walking to the right or left and then a response in the other direction (randomly determined). There were four trials for each target, two using the $20^{\circ}$ paths and two using the $40^{\circ}$ paths. The order of targets and path inclinations was randomly determined for each observer. Before the experimental trials, the observer received one full practice trial without feedback about accuracy of performance.

In the vision condition, the procedure was the same as in the no-vision condition, except that vision was allowed at all times. Thus, after the command to turn, the observer turned and attempted to walk straight to the target with both eyes open. There were four trials to each target, and these were distributed in the same way as in the no-vision condition.

In the visually directed walking task, the observer binocularly viewed the target from the origin (with auditory cues occluded), closed his or her eyes, and walked directly to the imaginally updated target location. Four responses were made to each target. Before the experimental trials, the observer received one practice trial without feedback. We refer to this condition as "direct walking."

\section{Results and Discussion}

The data of the two triangulation tasks were analyzed as in the two preceding experiments. Thus, mean indicated distance, based on two trials each, was computed for each observer, target, and condition; these means then were used to compute the grand means and standard errors shown in Figure 10.

The observer means were subjected to a repeated measures ANOVA with three variables (Target Distance $x$
Vision Availability $\times$ Path Inclination). The only statistically significant effect was the main effect of target distance, $F(2,38)=287.6, p<.001, M S E=9.16$. The exponents of the best-fitting power function for the data plotted in Figure 10 were 1.02 for $20^{\circ}$, no-vision; 0.98 for $20^{\circ}$, vision; 0.80 for $40^{\circ}$, no vision, and 1.04 for $40^{\circ}$, vision.

The triangulation results shown in Figures $10 \mathrm{~A}$ and $10 \mathrm{C}$ and the negative effect of vision and no vision in the ANOVA confirm the findings of the previous four experiments in indicating that perceived egocentric distance, averaged over observers, was accurate out to $15 \mathrm{~m}$.

For the direct walking task, the four responses to each target were averaged to obtain a mean indicated distance to that target for each observer. These means then were used to compute the grand means and standard errors shown in Figure 11. The exponent of the best-fitting power function was 0.92 . These data were in close agreement with the triangulation results of Figure 10 in showing accurate perception of distance out to $16 \mathrm{~m}$, with slight underestimation beyond that (at $22 \mathrm{~m}$ ).

\section{General Discussion}

In previous research, Loomis et al. (1992) introduced triangulation by pointing as a procedure for measuring perceived egocentric distance. Results of that research showed that target distances out to $5.7 \mathrm{~m}$ (the largest distance studied) were perceived accurately by the average observer under conditions providing an abundance of distance cues, primarily binocular parallax (convergence), binocular disparity, texture, and angular elevation (height in the field). In the current research, we used two triangulation procedures outdoors, where we could present targets at much greater distances. In two experiments we used triangulation by pointing, and in three we used triangulation by walking. Under viewing conditions that allowed an abundance of distance cues, results of the five experiments provide strong evidence that perceived distance, averaged over observers, is accurate out to $15 \mathrm{~m}$; with few exceptions, the errors associated with the mean triangulated distances were less than $1 \mathrm{~m}$. For target distances between 15 and $25 \mathrm{~m}$ (the largest distance studied), the evidence indicates slight underestimation.

Several studies using visually directed walking have demonstrated accurate mean performance out to $20 \mathrm{~m}$ (Corlett et al., 1985; Elliott, 1986, 1987; Elliott et al., 1990; Loomis et al., 1992; Rieser et al., 1990; Steenhuis \& Goodale, 1988; Thomson, 1983). Although those results would seem to indicate accurate perception of egocentric distance, other interpretations also have been proposed (Loomis et al., 1992). One hypothesis, in particular, is that observers systematically misperceive target distances but, through visuomotor coordination, are able to calibrate their walking to arrive at the target correctly. For example, if a target that is $15 \mathrm{~m}$ away appears to be, under full-cue conditions, only $12 \mathrm{~m}$ away, calibration of walking could nevertheless result in a walk of $15 \mathrm{~m}$. A difficulty with this hypothesis is that observers usually do not perform blind walking to pre- 
(A)

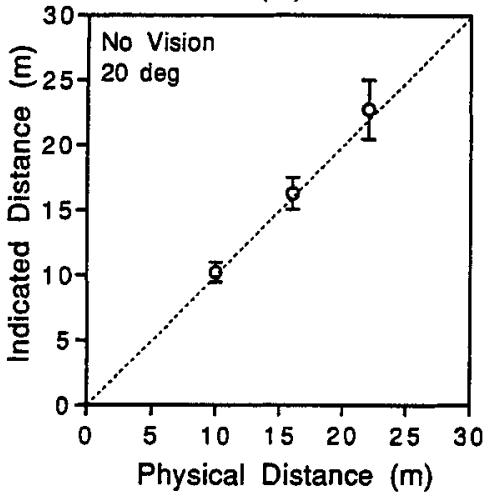

(C)

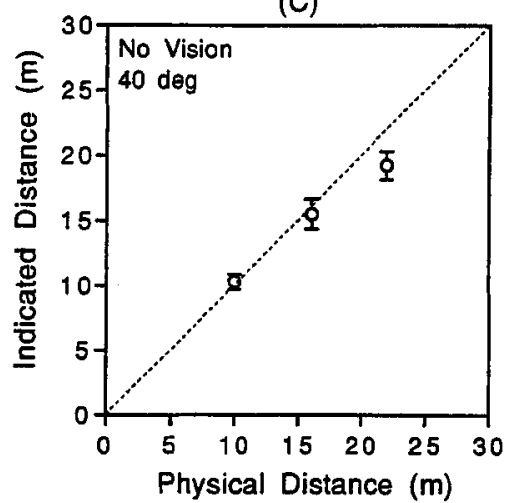

(B)

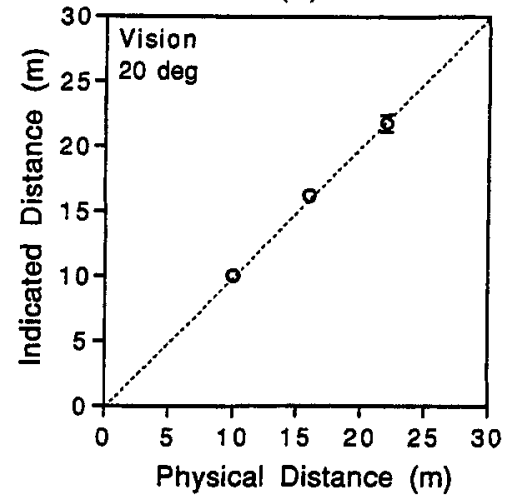

(D)

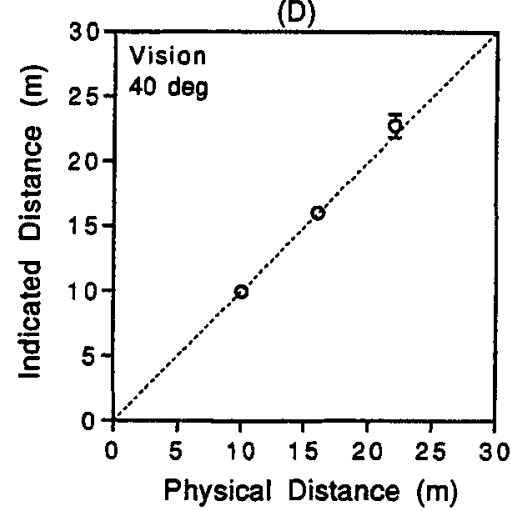

Figure 10. The triangulation results of Experiment 5. A: The mean indicated distances of the targets obtained from triangulation by walking in the no-vision condition; the inclination of the initial walking path was $20^{\circ}$. B: The mean indicated distances of the targets obtained from the directional walking response when vision was available continuously; the path inclination was $20^{\circ}$. $\mathrm{C}$ : The mean indicated distances of the targets obtained from triangulation by walking in the no-vision condition; the path inclination was $40^{\circ}$. D: The mean indicated distances of the targets obtained from the directional walking response when vision was available continuously; the path inclination was $40^{\circ}$. In all four panels, the error bars represent 1 SEM.

viewed targets that are more than $5 \mathrm{~m}$ away. Thus, it is difficult to imagine how this putative calibration is carried out for these distances.

The congruence of our triangulation results with those of visually directed walking (Experiment 5 and the aforementioned studies) constrains considerably the interpretation of both sets of results. If observers view a distant target and then, with eyes closed, indicate its location by a variety of "converging" responses (i.e., pointing toward it while walking by, walking directly to it, walking along an oblique path and then turning to walk toward it, and walking to it by way of an indirect path), the most plausible interpretation is that observers are responding to the perceived and imaginally updated target location.

The current results would have been even more forceful in compelling the interpretation of accurate perception of egocentric distances had we included conditions in which the target distances were misperceived. Philbeck and Loomis (1997) found that when distance cues are restricted greatly, visually directed walking exhibits large and system- atic error: Observers overwalk to near targets (e.g., $0.5 \mathrm{~m}$ ) and underwalk to far targets (e.g., $4 \mathrm{~m}$ ) when single-visual targets are presented at eye level. However, they did not use either of the triangulation methods used here. We predict the following results when triangulation methods are combined with manipulation of the availability of distance cues: Visually directed walking and triangulation methods will point to the indicated target location regardless of whether this indicated location is the physical target location. Figure 12 conveys the idea in the case of a target that is perceived closer than its physical distance. The figure depicts two different responses made without vision: direct and indirect walking. Whether the observer attempts to walk directly or indirectly to the target without vision following visual preview, he or she ought to end up at the location specified perceptually from the origin of locomotion. In a recent study involving direct and indirect walking, Philbeck, Loomis, and Beall (in press) confirmed these predictions under both full- and reduced-cue conditions. The trajectories of observers converged on roughly the same location in space, a 


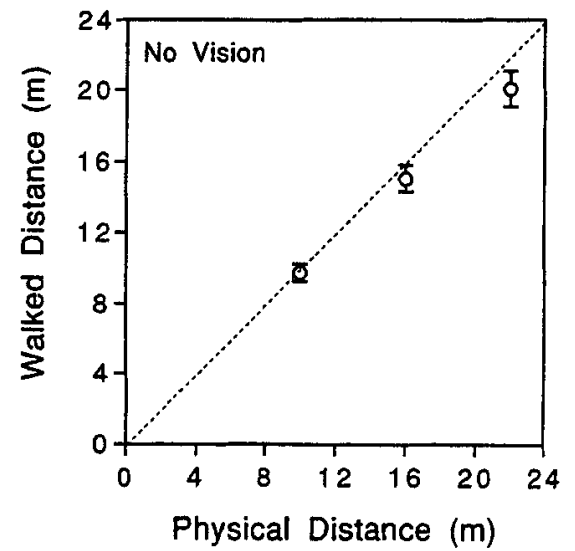

Figure 11. The direct walking results of Experiment 5 show the mean distances to the observers' terminal points in response to three targets varying in distance from the origin. The error bars represent 1 SEM.

location that was near the target under full cues but generally some distance away from the target under reduced cues. This result is evidence that observers are directing their actions toward the perceived target.

To pursue this reasoning a little more, consider what an observer would do if presented with a "virtual" object that the observer knows to be "virtual." Such a virtual object might be a virtual image produced by a beam-splitting plane mirror, a real image produced by a large condensing lens, a holographic real image, or a synthetic object produced by a virtual visual display. Even if the observer knows the object to be virtual, he or she ought to indicate the same location in space by way of the different converging responses mentioned earlier. Moreover, this location will be that of the perceived object. It should not matter whether there is a real object at that location or whether the observer knows it to be real or virtual; all that should matter is the perceived location of the stimulus, which is determined by the stimulus information and the perceptual processing of the observer.

Our earlier prediction that the observer will respond to the same location regardless of the type of response is predicated on there being no error in path integration (perception of self-motion), in imaginal updating, or in execution of the intended response. Clearly, this cannot be true because, at the least, there must be nonsystematic error in each constituent process. Assuming the existence of only nonsystematic error, the correct prediction is that the centroid of the responses by a single observer using one response will coincide with the centroid on any other response. The fact that the triangulation methods here provided results congruent with those from visually directed walking argues against systematic error in the constituent processes. This conclusion appears to be inconsistent with results obtained by Loomis et al. (1993) and Sadalla and Montello (1989) on path integration. However, their tasks involved passive guidance of the observer by an experimenter. It may be that when observers are able to actively guide their own loco- motion, as in our triangulation tasks, there is little or no systematic error in path integration for the short distances traveled.

Finally, we address the issue of how useful these triangulator procedures will be for assessing perceived egocentric distance of still more distant targets. We think that for these procedures to be used for target distances much greater than those studied here $(25 \mathrm{~m})$, it will be necessary to improve the precision of measurement. Increasing the triangulation base might seem to be a way to do this, but we are skeptical. Imaginally updating while walking $10-15 \mathrm{~m}$ is natural, but one's confidence in doing so for larger distances begins to fall off sharply. Hence, we doubt that increasing the triangulation base beyond $10-15 \mathrm{~m}$ will be of much value. The other possibility is to obtain many more directional responses to each target by each observer and then to average these before triangulating the imaginally updated target. We were able to average the azimuths in our pointing procedure, but our walking method, which seemed to be more natural, had the disadvantage of not allowing the averaging of the directional responses. This could be rectified by better constraining the turn location and obtaining either heading or course immediately after the turn. Thus, we believe that by averaging a sufficient number of directional responses, it ought to be possible to improve the precision of the triangulation method to allow the assess-

\section{Target}

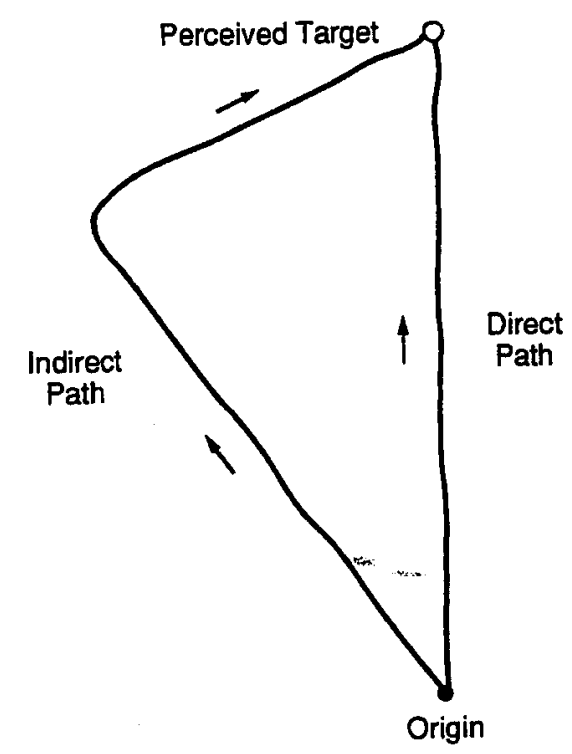

Figure 12. Congruence of direct and indirect walking. If the observer walks to the perceived and imaginally updated target location, he or she will walk to the same location whether walking along a direct or in indirect path (ignoring errors in self-motion perception and execution of the intended response). If there is perceptual error, this location will not coincide with that of the physical target. 
ment of perceived and updated target locations for targets whose initial distances are well beyond $25 \mathrm{~m}$.

\section{References}

Baird, J. C. (1970). Psychophysical analysis of visual space. New York: Pergamon Press.

Böök, A., \& Gärling, T. (1981). Maintenance of orientation during locomotion in unfamiliar environments. Journal of Experimental Psychology: Human Perception and Performance, 7, 995-1006.

Corlett, J. T. (1986). The effect of environmental cues on locomotor distance estimation by children and adults. Human Movement Science, 5, 235-248.

Corlett, J. T., Byblow, W., \& Taylor, B. (1990). The effect of perceived locomotor constraints on distance estimation. Journal of Motor Behavior, 22, 347-360.

Corlett, J. T., \& Patla, A. E. (1987). Some effects of upward, downward, and level visual scanning and locomotion on distance estimation accuracy. Journal of Human Movement Studies, 13, 85-95.

Corlett, J. T., Patla, A. E., \& Williams, J. G. (1985). Locomotor estimation of distance after visual scanning by children and adults. Perception, 14, 257-263.

Da Silva, J. A. (1985). Scales for perceived egocentric distance in a large open field: Comparison of three psychophysical methods. American Journal of Psychology, 98, 119-144.

Elliott, D. (1986). Continuous visual information may be important after all: A failure to replicate Thomson (1983). Journal of Experimental Psychology: Human Perception and Performance, $12,388-391$.

Elliott, D. (1987). The influence of walking speed and prior practice on locomotor distance estimation. Joumal of Motor Behavior, 19, 476-485.

Elliott, D., Jones, R., \& Gray, S. (1990). Short-term memory for spatial location in goal-directed locomotion. Bulletin of the Psychonomic Society, 8, 158-160.

Etienne, A. (1992). Navigation of a small mammal by dead reckoning and local cues. Current Directions in Psychological Science, $1,48-52$.

Foley, J. M. (1977). Effect of distance information and range on two indices of visually perceived distance. Perception, 6, 449-460.

Foley, J. M. (1980). Binocular distance perception. Psychological Review, 87, 411-434.

Foley, J. M., \& Held, R. (1972). Visually directed pointing as a function of target distance, direction, and available cues. Perception \& Psychophysics, 12, 263-268.

Gallistel, C. R. (1990). The organization of leaming. Cambridge, MA: MIT Press.

Gilinsky, A. S. (1951). Perceived size and distance in visual space. Psychological Review, 58, 460-482.

Gogel, W. C. (1974). Cognitive factors in spatial responses. Psychologia, 17, 213-225.

Gogel, W. C. (1977). The metric of visual space. In W. Epstein (Ed.), Stability and constancy in visual perception: Mechanisms and processes (pp. 129-181). New York: Wiley.

Gogel, W. C. (1982). Analysis of the perception of motion concomitant with a lateral motion of the head. Perception \& Psychophysics, 32, 241-250.

Gogel, W. C. (1990). A theory of phenomenal geometry and its applications. Perception \& Psychophysics, 48, 105-123.

Gogel, W. C. (1993). The analysis of perceived space. In S. C.
Masin (Ed.), Foundations of perceptual theory (pp. 113-182). Amsterdam: Elsevier.

Gogel, W. C., Loomis, J. M., Newman, N. J., \& Sharkey, T. J. (1985). Agreement between indirect measures of perceived distance. Perception \& Psychophysics, 37, 17-27.

Harway, N. I. (1963). Judgment of distance in children and adults. Journal of Experimental Psychology, 65, 385-390.

Holway, A. H., \& Boring, E. G. (1941). Determinants of apparent visual size with distance variant. American Joumal of Psychology, 54, 21-37.

Israel, I., \& Berthoz, A. (1992). Representations of space and motion in man. In G. E. Stelmach \& J. Requin (Eds.), Tutorials in motor behavior (pp. 195-209). Amsterdam: Elsevier.

Künnapas, T. (1968). Distance perception as a function of available visual cues. Journal of Experimental Psychology, 77, 523-529.

Laurent, M., \& Cavallo, V. (1985). Role des modalites de prise d'informations visuelles dans un pointage locomoteur. L'Annee Psychologique, 85, 41-48.

Laurent, M., \& Thomson, J. A. (1988). The role of visual information in control of a constrained locomotor task. Journal of Motor Behavior, 20, 17-37.

Loarer, E., \& Savoyant, A. (1991). Visual imagery in locomotor movement without vision. In R. H. Logie \& M. Denis (Eds.), Mental images in human cognition (pp. 35-46). Amsterdam: Elsevier.

Loomis, J. M., Da Silva, J.A., Fujita, N., \& Fukusima, S. S. (1992). Visual space perception and visually directed action. Journal of Experimental Psychology: Human Perception and Performance, 18, 906-921.

Loomis, J. M., Klatzky, R. L., Golledge, R. G., Cicinelli, J. G., Pellegrino, J. W., \& Fry, P. A. (1993). Nonvisual navigation by blind and sighted: Assessment of path integration ability. Journal of Experimental Psychology: General, 122, 73-91.

Mittelstaedt, H., \& Mittelstaedt, M. L. (1982). Homing by path integration. In F. Papi \& H. G. Walraff (Eds.), Avian navigation (pp. 290-297). New York: Springer.

Philbeck, J. W., \& Loomis, J. M. (1997). Comparison of two indicators of perceived egocentric distance under full-cue and reduced-cue conditions. Journal of Experimental Psychology: Human Perception and Performance, 23, 72-85.

Philbeck, J. W., Loomis, J. M., \& Beall, A. C. (in press). Visually perceived location is an invariant in the control of action. Perception \& Psychophysics.

Potegal, M. (1971). A note on spatial-motor deficits in patients with Huntington's disease: A test of a hypothesis. Neuropsychologia, 9, 233-235.

Potegal, M. (1972). The caudate nucleus egocentric localization system. Acta Neurobiologiae Experimentalis, 32, 479-494.

Presson, C. C., \& Montello, D. R. (1994). Updating after rotational and translational body movements: Coordinate structure of perspective space. Perception, 23, 1447-1455.

Rieser, J. J. (1989). Access to knowledge of spatial structure at novel points of observation. Joumal of Experimental Psychology: Learning, Memory, and Cognition, 15, 1157-1165.

Rieser, J. J., Ashmead, D. H., Talor, C. R., \& Youngquist, G. A. (1990). Visual perception and the guidance of locomotion without vision to previously seen targets. Perception, 19, 675689.

Rieser, J. J., \& Garing, A. E. (1994). Spatial orientation. In Encyclopedia of human behavior (Vol. 4, pp. 287-295). San Diego, CA: Academic Press.

Rieser, J. J., Guth, D. A., \& Hill, E. W. (1986). Sensitivity to 
perspective structure while walking without vision. Perception, 15, 173-188.

Rieser, J. J., Pick, H. L., Ashmead, D. H., \& Garing, A. E. (1995). Calibration of human locomotion and models of perceptualmotor organization. Journal of Experimental Psychology: Human Perception and Performance, 21, 480-497.

Sadalla, E. K., \& Montello, D. R. (1989). Remembering changes in direction. Environment and Behavior, 21, 346-363.

Sedgwick, H. A. (1986). Space perception. In K. R. Boff, L. Kaufman, \& J. P. Thomas (Eds.), Handbook of perception and human performance: Vol. 1. Sensory processes and perception (pp. 21.1-21.57). New York: Wiley.

Steenhuis, R. E., \& Goodale, M. A. (1988). The effects of time and distance on accuracy of target-directed locomotion: Does an accurate short-term memory for spatial location exist? Joumal of Motor Behavior, 20, 399-415.
Teghtsoonian, M., \& Teghtsoonian, R. (1969). Scaling apparent distance in a natural indoor setting. Psychonomic Science, 16, 281-283.

Teghtsoonian, R., \& Teghtsoonian, M. (1970). Scaling apparent distance in a natural outdoor setting. Psychonomic Science, 21, 215-216.

Thomson, J. A. (1980). How do we use visual information to control locomotion? Trends in Neurosciences, 3, 247-250.

Thomson, J. A. (1983). Is continuous visual monitoring necessary in visually guided locomotion? Journal of Experimental Psychology: Human Perception and Performance, 9, 427-443.

Received October 14, 1994

Revision received August 21, 1995

Accepted October 3, 1995 